\title{
RESEARCH
}

Open Access

\section{DKK3 attenuates JNK and AP-1 induced inflammation via Kremen-1 and DVL-1 in mice following intracerebral hemorrhage}

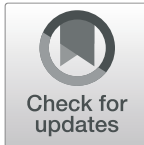

Yang $X u^{1,2,3}$, Derek Nowrangi ${ }^{2}$, Hui Liang ${ }^{4}$, Tian Wang ${ }^{2}$, Lingyan $\mathrm{Yu}^{2}$, Tai Lu ${ }^{2}$, Zhengyang Lu ${ }^{2}$, John H. Zhang ${ }^{2,5}$, Benyan Luo ${ }^{4^{*}}$ and Jiping Tang ${ }^{2^{*}}$

\begin{abstract}
Background: Intracerebral hemorrhage $(\mathrm{ICH})$ is the most devastating stroke subtype, with a poor prognosis and few proven treatments. Neuroinflammation is associated with $\mathrm{ICH}$-induced brain injury and unfavorable outcomes. There is growing evidence that Dickkopf (DKK) 3 plays a key role in the adaptive anti-inflammatory and neuroprotective responses following intracerebral hemorrhage. This study aimed to evaluate the protective effects of DKK3 against brain edema and neuroinflammation in a mice model of $\mathrm{ICH}$.

Methods: Male, adult CD1 mice were subjected to sham or ICH surgery using a collagenase injection model. ICH animals received either recombinant DKK3, Kremen-1 siRNA, or DVL-1 siRNA. The neurobehavioral deficits were evaluated at $24 \mathrm{~h}, 72 \mathrm{~h}$, and 28 days after ICH induction. Western blot and immunofluorescence were employed to examine the expression and localization of DKK3, Kremen-1, Dishevelled-1 (DVL-1), c-JUN N-terminal kinase (JNK), Activator protein-1 (AP-1), cleaved caspase-1, NF-KB, and IL-1 $\beta$ in the brain.

Results: The expression of endogenous DKK3 and DVL-1 was transiently decreased after ICH compared to that in the sham group. Compared to the mice of $\mathrm{ICH}$, exogenous rDKK3 administration reduced the brain water content and affected the neurological functions in ICH mice. Moreover, DKK3 was colocalized with Kremen-1 in microglia. Using a Kremen-1 or DVL-1 siRNA-induced in vivo knockdown approach, we demonstrated that the effects of DKK3 against ICH were mediated, at least partly, by the Kremen-1 and DVL-1 pathways.
\end{abstract}

Conclusions: DKK3 improves the neurological outcomes, potentially by decreasing JNK/AP-1-mediated inflammation, thereby ameliorating the short- and long-term sequelae after $\mathrm{ICH}$.

Keywords: Intracerebral hemorrhage, Inflammation, Dickkopf 3, Kremen-1, Dishevelled-1

\footnotetext{
* Correspondence: luobenyan@zju.edu.cn; jtang@llu.edu

${ }^{4}$ Department of Neurology, The First Affiliated Hospital, School of Medicine, Zhejiang University, Qingchun Road 79, Zhejiang 310003, Hangzhou, China ${ }^{2}$ Department of Basic Sciences, Division of Physiology, Loma Linda University School of Medicine, 11041 Campus St, Risley Hall, Room 219, Loma Linda, CA 92350, USA

Full list of author information is available at the end of the article
}

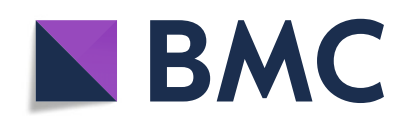

(- The Author(s). 2020 Open Access This article is licensed under a Creative Commons Attribution 4.0 International License, which permits use, sharing, adaptation, distribution and reproduction in any medium or format, as long as you give appropriate credit to the original author(s) and the source, provide a link to the Creative Commons licence, and indicate if changes were made. The images or other third party material in this article are included in the article's Creative Commons licence, unless indicated otherwise in a credit line to the material. If material is not included in the article's Creative Commons licence and your intended use is not permitted by statutory regulation or exceeds the permitted use, you will need to obtain permission directly from the copyright holder. To view a copy of this licence, visit http://creativecommons.org/licenses/by/4.0/. The Creative Commons Public Domain Dedication waiver (http://creativecommons.org/publicdomain/zero/1.0/) applies to the data made available in this article, unless otherwise stated in a credit line to the data. 


\section{Background}

Intracerebral hemorrhage ( $\mathrm{ICH}$ ) accounts for $10-15 \%$ of all strokes that has a mortality that far exceeds those of ischemic strokes. The lack of specific therapeutic targets for $\mathrm{ICH}$ stresses the need for developing new therapeutic regimens [1]. The primary brain injury occurs within a few minutes to a few hours after the onset of $\mathrm{ICH}$ in which the initial hematoma causes local tissue destruction from the mass effect. A secondary injury phase occurs from the breakdown of cell debris and blood components which can persist in the area surrounding the adjacent hematoma for several weeks [2]. Increasing evidence has shown that neuroinflammation plays a critical role in the secondary brain injury following $\mathrm{ICH}[3-7]$.

Some studies have shown that Dickkopf (DKK) 3 promotes cell survival by suppressing superoxide-producing enzyme or by inhibiting inflammation $[8,9]$. DKK3 is classified as a DKK glycoprotein family member that regulates cell fate during embryogenesis. DKK3 mediates potent antitumor effects, including reducing cell proliferation, anchorage-independent growth, and metastasis [10-12]. DKK3 antagonizes Wnt signaling by interacting with low-density lipoprotein receptor-related protein (LRP) 5/6 [13]. Therefore, DKK3 has been identified as a negative regulator of Wnt signaling in a complex and context-dependent manner [14]. Wnt principally involves the noncanonical ( $\beta$-catenin-independent) and the canonical ( $\beta$-catenin-dependent) signaling pathways [15]. Kremen-1 is a novel transmembrane receptor which function is Wnt inhibitory by removing LRP5/6 from the cell surface via clathrin-mediated endocytosis $[16,17]$. Dishevelled-1 (DVL-1) is a central component protein that relays Wnt signaling in both canonical and non-canonical pathways whose activity and stability are strictly controlled [18]. The noncanonical pathways are also involved in c-JUN N-terminal kinase (JNK) activation, which produces dominant-negative JNK and prevents pressure overload. Additionally, calmodulindependent protein kinase II (CAMKII) phosphorylation was associated with increased histone deacetylase phosphorylation [18]. The activation of the JNK/Activator protein-1 (AP-1) signaling pathways is attributable to the increased expression of inflammatory factors in the brain [19].

DKK3, a secretory glycoprotein, is released from tissues of mice under physiological conditions in the retina, oral submucous, and brain [20-22]. In myocardial infarction conditions, the absence of DKK3 increased the mortality and infarct size, along with an increase in cardiomyocyte apoptosis and inflammation [9]. As a smooth muscle cell differentiation factor, the absence of DKK3 also leads to atherosclerotic plaque formation by increasing vascular inflammation [23]. The inhibition of inflammation in myocardial infarction might be associated with the regulation of the NF-kB pathway, which is also a cardioprotective regulator of pathological cardiac hypertrophy. This function largely occurs through the inactivation of apoptosis signal-regulating kinase (ASK1)/JNK/p38 signaling [24]. Consistent with above reports, DKK3 overexpression substantially alleviated cardiac hypertrophy and fibrosis $[25,26]$.

Currently, the mechanisms by which DKK3 modifies the inflammatory process in brain tissues are unclear. This study aims to determine the anti-inflammatory outcomes and mechanism of DKK3 in a mice model of $\mathrm{ICH}$.

\section{Material and methods \\ Animals}

This study was approved by the Institutional Animal Care and Use Committee at Loma Linda University. All procedures were carried out in compliance with the guidelines for Animal Experimentation of Loma Linda University. A total of 174 male CD1 mice (8-week-old, weight 30-35 g; Charles River, Wilmington, MA, USA) were used. The animals were housed in a temperaturecontrolled environment with a 12-h light/dark cycle.

\section{Experimental protocol}

In the present study, all mice were randomly assigned to the following four separate experiments which are shown in the timeline of experimental design. The experimental groups and number of animals used in experiments are listed in Fig. 1.

\section{Experiment 1}

To evaluate the time course expression of endogenous DKK3 Kremen-1, DVL-1 and phosphorylated-JNK (pJNK) in ICH mice, 36 animals were randomly divided into 6 groups for western blot: sham and 3, 6, 12, 24, and $72 \mathrm{~h}$ after $\mathrm{ICH}$.

\section{Experiment 2}

To assess the short- and long-term neurobehavioral function, 48 mice were divided into 8 groups: sham, ICH $24 \mathrm{~h}, \mathrm{ICH} 24 \mathrm{~h}+\mathrm{rDKK} 30.5 \mu \mathrm{g}$, ICH $24 \mathrm{~h}+\mathrm{rDKK} 3$ $1.5 \mu \mathrm{g}$, ICH $24 \mathrm{~h}+\mathrm{rDKK} 35 \mu \mathrm{g}$, sham $72 \mathrm{~h}, \mathrm{ICH} 72 \mathrm{~h}$, and $\mathrm{ICH} 72 \mathrm{~h}+\mathrm{rDKK} 3$ best dosage. The brain edema and neurobehavior tests were evaluated at 24 and $72 \mathrm{~h}$ post-ICH. The Morris water maze test and rotarod test were conducted on day 28 post-ICH.

\section{Experiment 3}

To determine the DKK3 intracellular localization in $\mathrm{ICH}$ mice, 36 animals were randomly divided into 3 groups: sham, ICH, and $\mathrm{ICH}+\mathrm{rDKK} 3$. The cellular localization of DKK3 was evaluated using double-labeling 


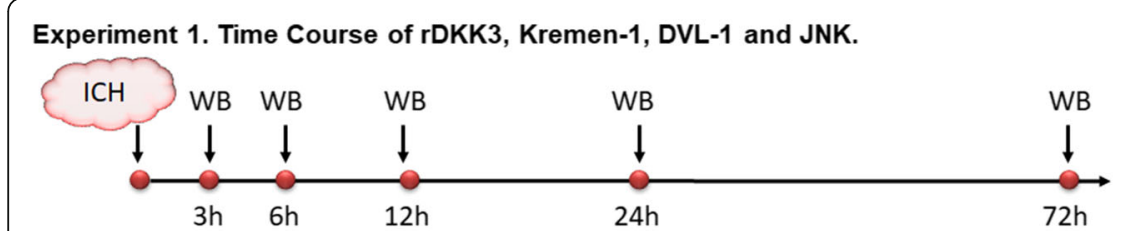

Experiment 2. The effective of rDKK3 treatment on brain edema and neurobehavior

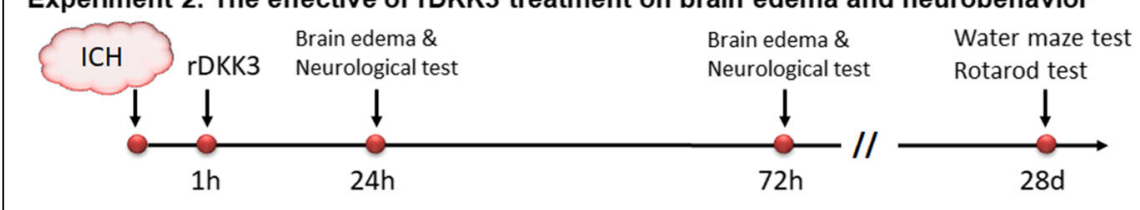

Groups:

1. Sham $24 \mathrm{~h} n=6$

2. $\mathrm{ICH} 3 \mathrm{~h} \quad \mathrm{n}=6$

3. $\mathrm{ICH} 6 \mathrm{~h} \quad \mathrm{n}=6$

4. $\mathrm{ICH} 12 \mathrm{~h} \quad \mathrm{n}=6$

5. $\mathrm{ICH} 24 \mathrm{~h} \quad \mathrm{n}=6$

6. $\mathrm{ICH} 72 \mathrm{~h} \quad \mathrm{n}=6$

Groups:

1.Sham 24h $n=6$

ICH $24 \mathrm{~h}+$ vehicle $\quad \mathrm{n}=6$

$3.1 \mathrm{CH} 24 \mathrm{~h}+\mathrm{rDKK} 30.5 \mathrm{ug} \quad \mathrm{n}=6$

$4.1 \mathrm{CH} 24 h+\mathrm{rDKK} 31.5 \mathrm{ug} \quad \mathrm{n}=6$

$5 . \mathrm{ICH} 24 \mathrm{~h}+\mathrm{rDKK} 3$ 5ug $\quad \mathrm{n}=6$

6. Sham $72 \mathrm{~h} \quad \mathrm{n}=6$

$7.1 \mathrm{CH} 72 \mathrm{~h}+$ vehicle $\quad \mathrm{n}=6$

$\begin{array}{ll}9 . S h a m ~ 28 d & n=6\end{array}$

10.1CH $28 d+$ vehicle $\quad n=6$

Experiment 3. DKK3 and Kremen-1 cellular localization.

11. ICH 28d + rDKK3 best dosage $n=6$

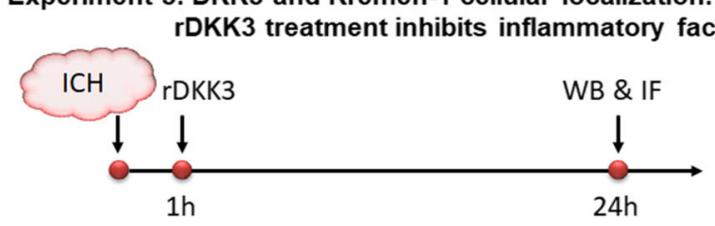

Groups:

1. Sham 24h $n=12$

2. $1 \mathrm{CH} 24 \mathrm{~h} \quad \mathrm{n}=12$

3. ICH $24 h+r D K K 3 \quad n=12$

Experiment 4. Kremen-1 siRNA or DVL-1 siRNA revise the neuroprotective effects of rDKK3

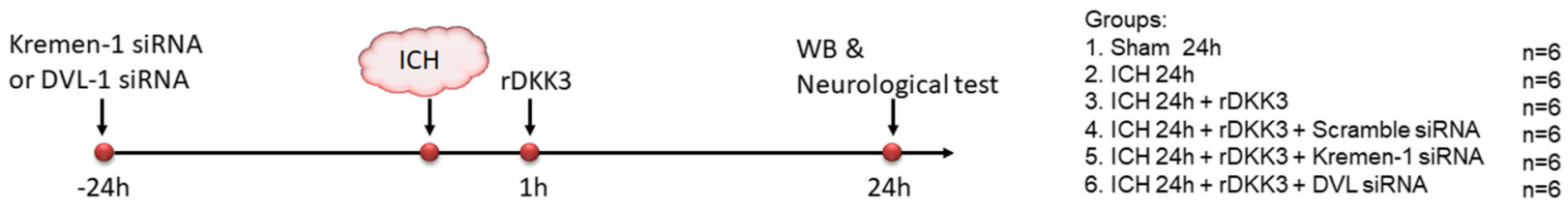

Fig. 1 Study design. Representative figure showing experimental design and number of animals for each group. ICH, intracerebral hemorrhage; WB, western blot; rDKK3, recombinant DKK3

immunofluorescence labeling to co-localize DKK3 with ionized calcium-binding adaptor molecule 1 (Iba-1), neuronal-specific nuclear protein (Neun), and Kremen-1.

\section{Experiment 4}

To explore the underlying mechanisms of DKK3mediated anti-inflammatory effects in ICH mice, Kremen-1 siRNA and DVL-1 siRNA were administered by intracerebroventricular (ICV) injection at $24 \mathrm{~h}$ before ICH induction. Thirty-six mice were randomly divided into 6 groups: sham, ICH, ICH + rDKK3, ICH + rDKK3 + scramble siRNA, ICH + rDKK3 + Krenam-1 siRNA, and $\mathrm{ICH}+\mathrm{rDKK} 3+$ DVL siRNA. Neurobehavioral tests and western blot analysis were performed at $24 \mathrm{~h}$ after $\mathrm{ICH}$.

\section{Intracerebral hemorrhage induction}

$\mathrm{ICH}$ was induced via injection of collagenase into right basal ganglia as described [27]. After induction of anesthesia with ketamine $(100 \mathrm{mg} / \mathrm{kg})$ and xylazine $(10$ $\mathrm{mg} / \mathrm{kg}$ ), animals were positioned prone in a stereotaxic frame (David Kopf Instruments, Tujunga, CA, USA). An electronic thermostat-controlled warming blanket was used to maintain the core temperature at $37^{\circ} \mathrm{C} \pm 0.5^{\circ} \mathrm{C}$. The collagenase $(0.075$ units in $0.5 \mu \mathrm{l}$ saline, VII-S; Sigma, MO, USA) was injected into the right basal ganglia. A 26-G needle was inserted with stereotaxic guidance coordinates $0.2 \mathrm{~mm}$ anterior, $3.5 \mathrm{~mm}$ ventral, and $2.2 \mathrm{~mm}$ lateral to the bregma at a rate of $0.1667 \mu \mathrm{l} / \mathrm{min}$ by a micro-infusion pump (Harvard Apparatus Inc., South Natick, MA, USA). Following the infusion, the needle was left in position for an additional $10 \mathrm{~min}$ after injection to prevent the leakage of collagenase, slowly retracted, and the incision was sutured. The sham group operation received only needle insertion.

\section{Assessment of neurological deficits}

Neurological functions including modified Garcia test, wire hanging, beam balance, and limb placement were evaluated in a blinded fashion [28]. An independent researcher was blinded to the experimental design and conducted the exams at $24 \mathrm{~h}, 72 \mathrm{~h}$, and 28 days after $\mathrm{ICH}$. The Garcia test includes the evaluation of spontaneous activity, axial sensation, vibrissae proprioception, symmetry of limb movement, lateral turning, forelimb walking, and climbing. 
In the long-term neurological study, we utilized the Morris water maze to test spatial learning capacity and memory function recovery according to previous studies $[3$, 27]. Starting from a semi-random location, each mouse is permitted to search for a partially submerged platform for $60 \mathrm{~s}$. Next, the mice were guided to the platform and allowed to remain for $5 \mathrm{~s}$. The probe trial was carried out on the last day of the exam. Following learning trial, the platform was removed. The swimming path, frequency of platform crossings, latency of first platform crossing, and frequency of correct quadrant crossings were recorded with a camera and linked to a computer tracking system (Noldus Ethovision, WA, USA). We also utilized the rotarod test to assess sensorimotor coordination and balance $[29,30]$. The speed of a cylinder was slowly increased from 4 to $40 \mathrm{rpm}$ over 5 min. The mice were allowed to run on the cylinders until they fell off and the times recorded. Each mouse was then tested three times, and the average retention time on rotarod was recorded. The mice were trained prior to testing with the average time elapsed from the rotation of the cylinder recorded as the baseline latency.

\section{Evaluation of brain water content}

Mice were euthanized at $24 \mathrm{~h}$ or $72 \mathrm{~h}$ post-ICH. The brains were immediately removed and dissected into 5 parts: ipsilateral and contralateral basal ganglia and cortex. The cerebellum was used as the internal control [31]. Each part was weighed on an electronic analytical balance (APX-60, Denver Instrument, NY, USA) giving the wet weight (WW) and then dried at $100{ }^{\circ} \mathrm{C}$ for $24 \mathrm{~h}$ to determine the dry weight (DW). The brain water content was calculated as $[(\mathrm{WW}-\mathrm{DW}) / \mathrm{WW}] \times 100 \%$.

\section{Drug and siRNA administration}

Three different formats of Kremen-1 siRNA or DVL-1 siRNA (OriGene Technologies, MD, USA) were diluted with transfection reagent (EntranserTM, Engreen Biosystem). ICV administration was performed at $24 \mathrm{~h}$ before ICH as described [32-34]. The Kremen-1 siRNA, DVL-1 siRNA, and scramble siRNA mixture $(100 \mathrm{pmol}$ in $2 \mu \mathrm{l})$ was delivered into the ipsilateral ventricle, administration at a rate of $0.667 \mu \mathrm{l} / \mathrm{min}$. rDKK3 (SRP6268, SigmaAldrich, MO, USA) was dissolved in $10 \mu \mathrm{l}$ of saline, and three different doses $(0.5 \mu \mathrm{g}, 1.5 \mu \mathrm{g}$, and $5.0 \mu \mathrm{g}$ per mouse) were designed. rDKK3 was administered via intranasal route at $1 \mathrm{~h}$ post-ICH.

\section{Western blot analysis}

Mice hemispheres were isolated and stored at $-80^{\circ} \mathrm{C}$ until protein extraction. The ipsilateral brain hemispheres were homogenized in RIPA lysis buffer (sc24948, Santa Cruz, TX, USA) and then centrifuged (14, $000 \mathrm{~g}$ at $4{ }^{\circ} \mathrm{C}$ for $\left.30 \mathrm{~min}\right)$. Equal amounts of protein
$(50 \mu \mathrm{g})$ were loaded and subjected to electrophoresis on an SDS-PAGE gel. After being transferred to a nitrocellulose membrane, they are blocked with 5\% nonfat milk (Bio-Rad Laboratories, Irvine, CA, USA). The membrane was incubated with the primary antibody overnight at $4{ }^{\circ} \mathrm{C}$. The primary antibodies were used as follows: anti-DKK3 (1:1000, ab186409, Abcam, MA, USA), anti-Kremen-1 (1:500, ab86636, Abcam, MA, USA), anti-DVL-1 (1:1000, ab174679, Abcam, MA, USA), anti-AP-1 (1:200, NBP1-89544, Novusbio, CO, USA), anti-caspase-1 (1:1000, NBP1-45433, Novusbio, CO, USA), anti-IL-1 $\beta$ (1:500, sc-7884, Santa Cruz, TX, USA), and anti-p-c-Jun N-terminal kinase (p-JNK) (1: 500, ab131499, Abcam, MA, USA). The blot bands were quantified using Image $(\mathrm{NIH})$. The results were expressed as ratio of the target band intensity to the band intensity of $\beta$-actin (1:1000, sc-58673, Santa Cruz, TX, USA) and then normalized to the mean sham group ratio.

\section{Immunofluorescence staining}

Mice were perfused under deep anesthesia with isoflurane, followed by infusion of $4 \%$ paraformaldehyde. The brains were then removed and fixed in formalin at $4{ }^{\circ} \mathrm{C}$ overnight followed by dehydration with $30 \%$ sucrose in PBS. The frozen coronal slices $(10 \mathrm{~mm}$ thick) were sectioned in cryostat (CM3050S; Leica Microsystems, Bannockburn). Brain slices were hydrated and blocked with $5 \%$ normal goat serum. Sections were incubated overnight at $4{ }^{\circ} \mathrm{C}$ with the following primary antibodies: anti-DKK3 (1:100, ab186409, Abcam, MA, USA) and anti-Kremen-1 (1:100, ab86636, Abcam, MA, USA). Then, they were incubated by appropriate fluorescenceconjugated secondary antibodies (1:100, AB2337972, AB2338059, AB2340432, or AB233887, Jackson ImmunoResearch Laboratories, PA, USA) at room temperature for $2 \mathrm{~h}$. Sections were observed using an OLYMPUS BX51 microscope.

\section{Statistical analysis}

All values are presented in the text as mean \pm standard deviation (SD). Western blot data were analyzed using one-way ANOVA with Tukey post hoc tests. Behavior data were analyzed using one-way ANOVA on ranks with Tukey post hoc tests or repeated measures ANOVA when appropriate. All histological data were analyzed using one-way ANOVA with StudentNewman's post hoc tests. Statistical significance implies $p<0.05$.

\section{Results}

Endogenous levels of DKK3, Kremen-1, DVL-1, and p-JNK in $\mathrm{ICH}$ mice

Western blotting showed that the expression of DKK3 transiently decreased after ICH (* $p<0.05$ versus sham; 
Fig. 2b) compared to that of the sham group at 6 to $72 \mathrm{~h}$ after ICH. Kremen-1 showed no change at any time point (Fig. 2c). DVL-1 decreased at $12 \mathrm{~h}$ after ICH $(p<$ 0.05 versus sham; Fig. $2 \mathrm{~d}$ ). An elevation of $\mathrm{p}$-JNK was observed at $3 \mathrm{~h}$ and reached a peak at $12 \mathrm{~h}$ after $\mathrm{ICH}$. The level of p-JNK began to decline at $24 \mathrm{~h}$ but remained statistically significant to sham through $72 \mathrm{~h}(p$ $<0.05$ versus sham; Fig. 2e).

\section{rDKK3 improved the neurological functions and reduced} the brain water content at 24 and $72 \mathrm{~h}$ after $\mathrm{ICH}$

Three different doses of $\mathrm{rDKK} 3(0.5 \mu \mathrm{g}, 1.5 \mu \mathrm{g}$, and $5.0 \mu \mathrm{g}$ ) were administered intranasally at $1 \mathrm{~h}$ after ICH induction. The mice in the vehicle group showed statistically decreased performance in the Garcia test, limb placement test, and corner turn test at both $24 \mathrm{~h}$ and $72 \mathrm{~h}$ after $\mathrm{ICH}$ compared to those of the sham group (Fig. 3a-f). rDKK3 $(5.0 \mu \mathrm{g})$ improved the neurological functions in all the same tests at 24 and $72 \mathrm{~h}$ after $\mathrm{ICH}$ compared to those in the vehicle group $(p<0.05$ versus vehicle).

The brain water content in the vehicle group showed significant elevation in ipsilateral basal ganglia at both 24 and $72 \mathrm{~h}$ (" $p<0.05$ versus sham; Fig. $3 \mathrm{~g}$, h). Compared to the vehicle group, rDKK3 treatment reduced the $\mathrm{ICH}$-induced brain water content in the ipsilateral basal ganglia at 24 and $72 \mathrm{~h}$ after ICH $\left({ }^{\#} p<0.05\right.$ versus vehicle). The 24-h results indicated that the high dose of rDKK3 $(5.0 \mu \mathrm{g})$ showed the greatest improvements and was thus selected as the dosage for the 72-h experiment and other experiments.

\section{rDKK3 improved long-term neurobehavior}

To examine the long-term neurological impairment and neurological function, the Morris water maze test and rotarod test were performed at 4 weeks post-ICH [35]. The results showed that the escape latency and swimming distance of the vehicle group were significantly longer compared to sham $(" p<0.05$ versus sham; Fig. 4a, b). The rDKK3 group exhibited an improved performance in escape latency and swimming distance on the 5th day of training compared to vehicle. Though not statistically significant to vehicle $(p>0.05)$, rDKK3 did show improvement by not being statistically significant to sham in the probe quadrant duration (Fig. 4c). However, comparing the velocity did not show significant changes between any of the groups $(p>0.05$; Fig. $4 d)$. The rotarod test showed no changes between the vehicle and rDKK3 groups at 7 days after the surgery. However, rDKK improved the performance in the rotarod test at 28 days after ICH $\left({ }^{\#} p<0.05\right.$ versus vehicle; Fig. 4e).

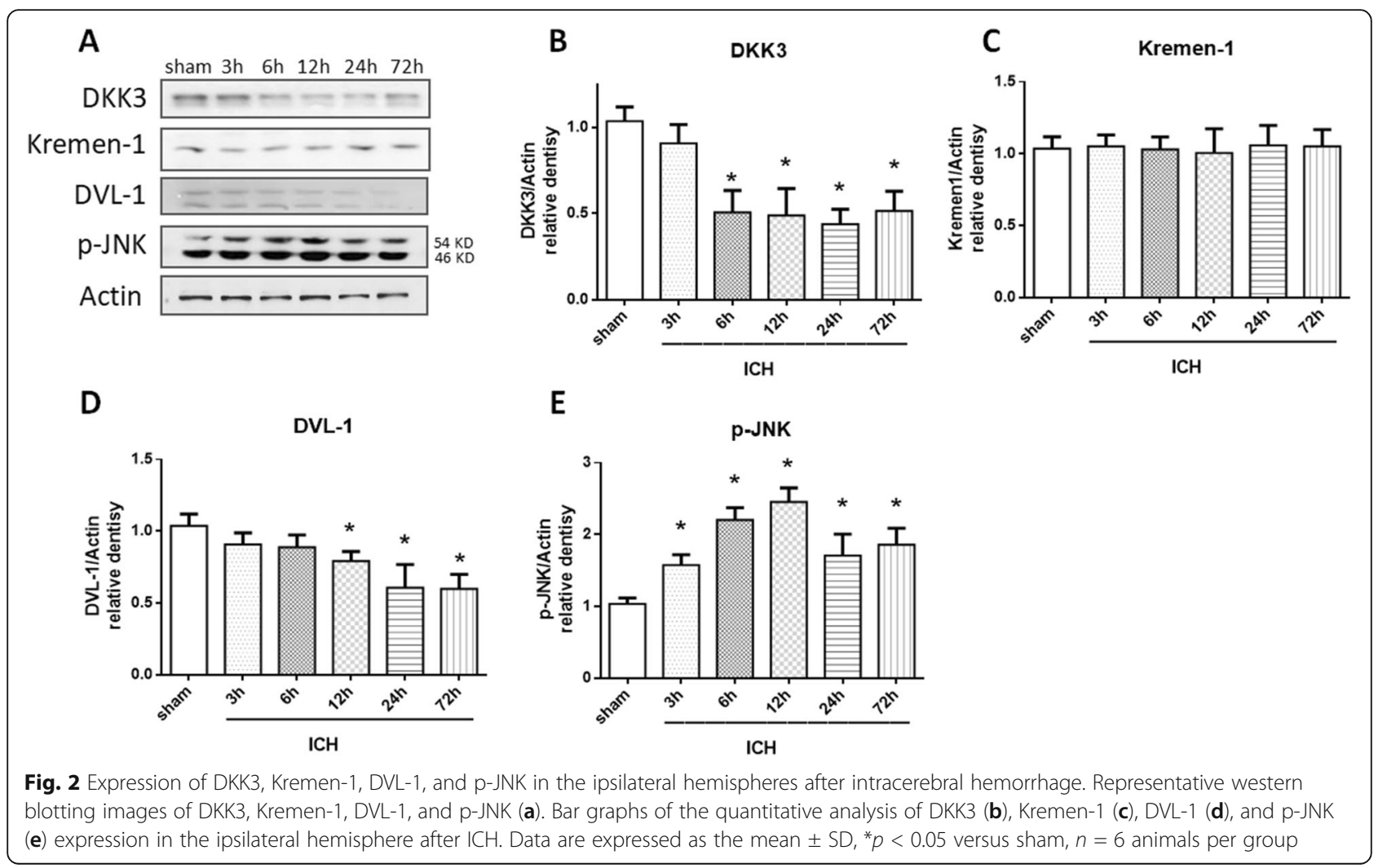




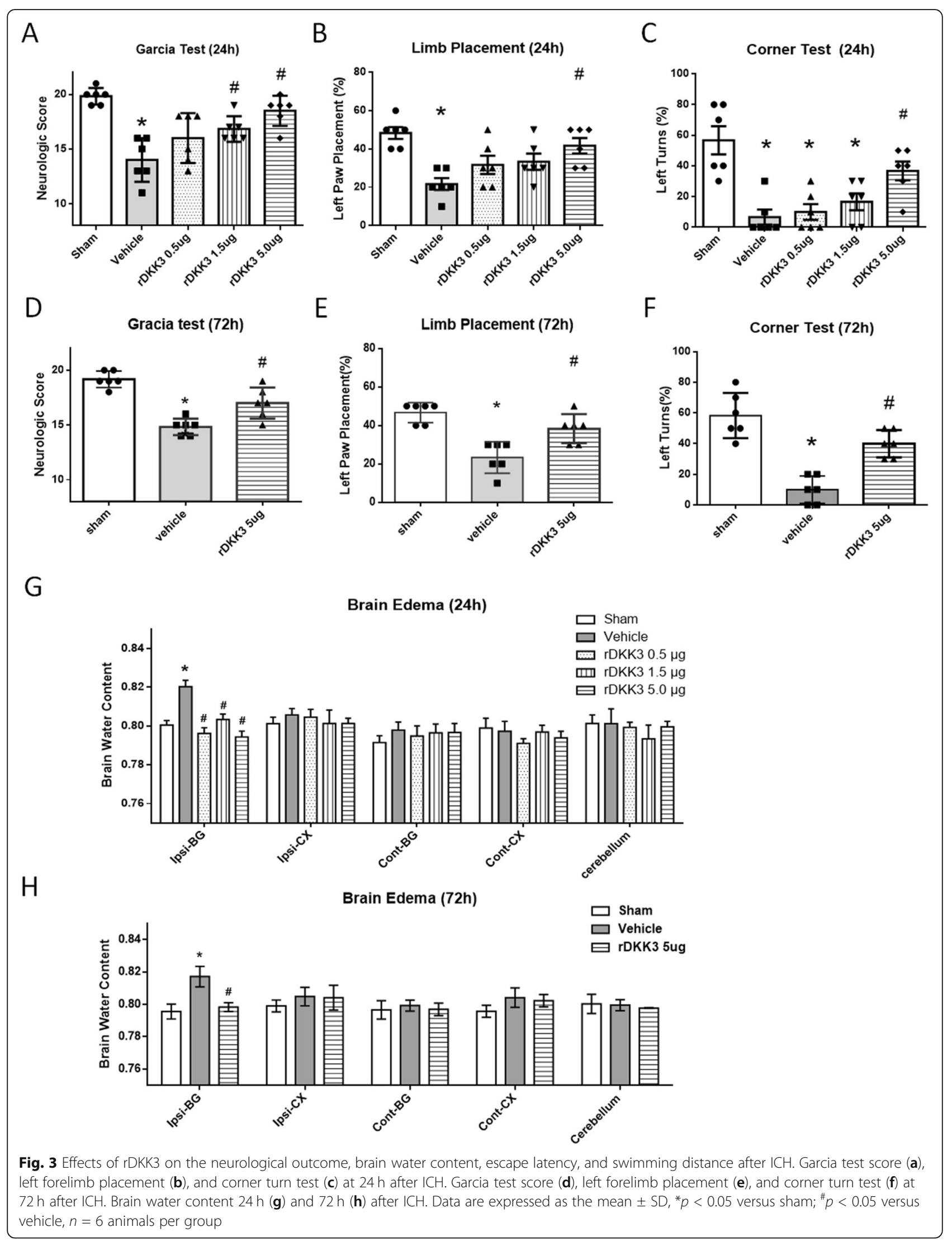




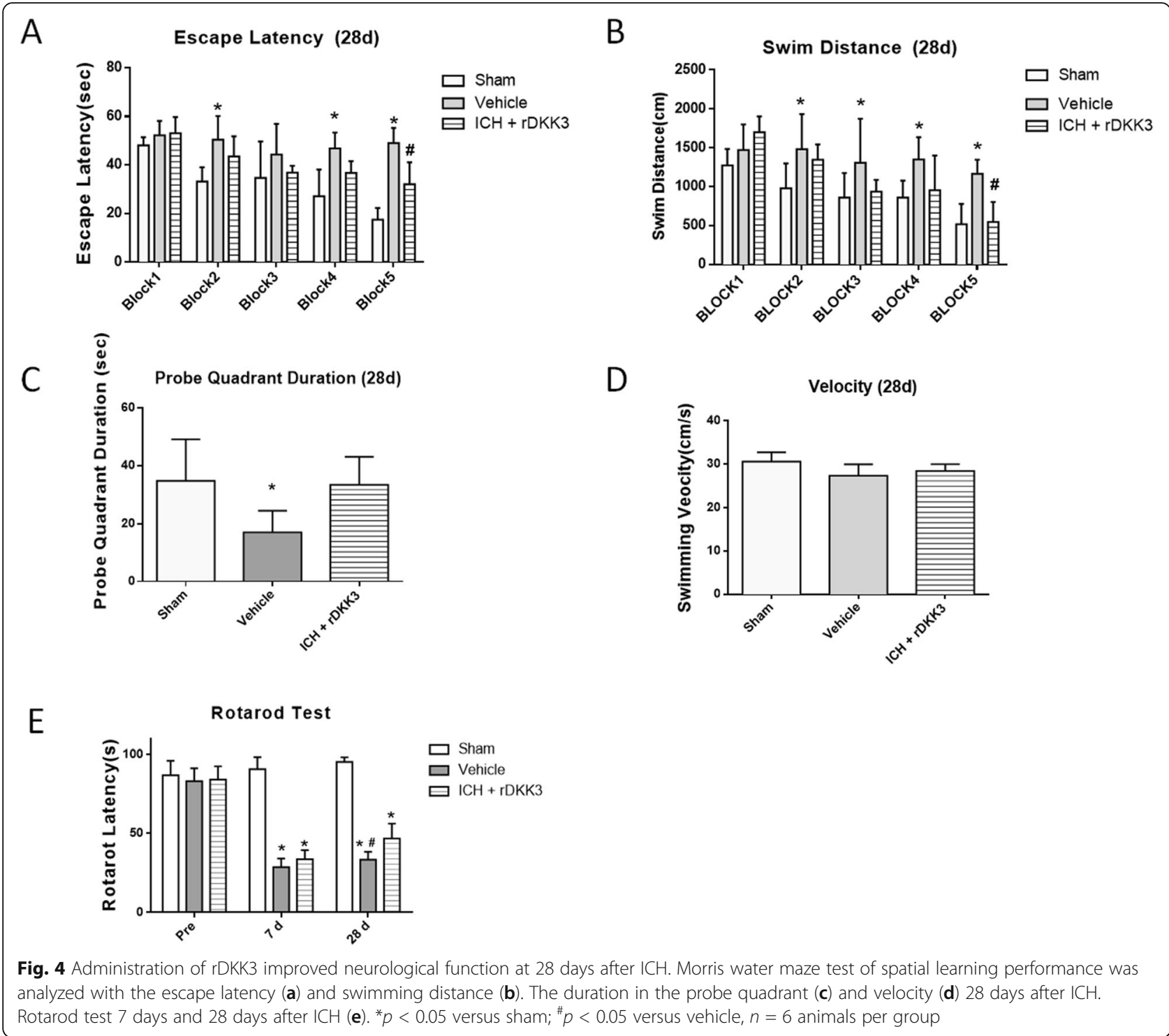

rDKK3 treatment reduces the expression of inflammatory markers after ICH

The vehicle group showed a decreased expression of DKK3 after ICH at $24 \mathrm{~h}$ consistent with our results ( ${ }^{*} p<$ 0.05 versus sham; Fig. 5a, b). After rDKK3 administration, the total level of DKK3 increased when compared with the vehicle group ${ }^{\#} p<0.05$ versus vehicle; Fig. 5a, b). Inflammatory factors, including TNF- $\alpha$ and IL-1 $\beta$ expression, increased after $\mathrm{ICH}$ in the vehicle group compared to sham $(* p<0.05$; Fig. $5 \mathrm{a}, \mathrm{c}, \mathrm{d})$. rDKK3 administration reversed these changes and showed significantly decreased expression of TNF- $\alpha$ and IL- $1 \beta$ as compared to vehicle $\left({ }^{\#} p<0.05\right.$; Fig. $\left.5 \mathrm{a}, \mathrm{c}, \mathrm{d}\right)$. The immunofluorescence results showed that the fluorescence intensity of DKK3 outside of the cell membrane in vehicle and DKK3 treatment groups was slightly reduced when compared to sham (Fig. 5e).

\section{Co-localization of DKK3 and Kremen-1 in microglia and} neurons after ICH

Dual-immunofluorescence staining was performed in the perihematomal brain tissue $24 \mathrm{~h}$ following hemorrhage induction. The staining showed that both DKK3 and Kremen-1 were colocalized with microglia (CD68) and neurons (Neun; Fig. 6b, c). Interestingly, most of Kremen-1 was visualized as a ring. Immunofluorescence co-labeling of DKK3 with Kremen-1 was detected in the vehicle group (Fig. 6d).

Knockdown of Kremen-1 or DVL-1 reversed the effects of the rDKK3-mediated inhibition of inflammation after ICH The ICH mice were given $\mathrm{rDKK} 3$ in addition to either Kremen-1 siRNA, DVL-1 siRNA, or scramble siRNA. Western blot analysis was done at $24 \mathrm{~h}$ after ICH (Fig. 7a). Results showed that the expression of 


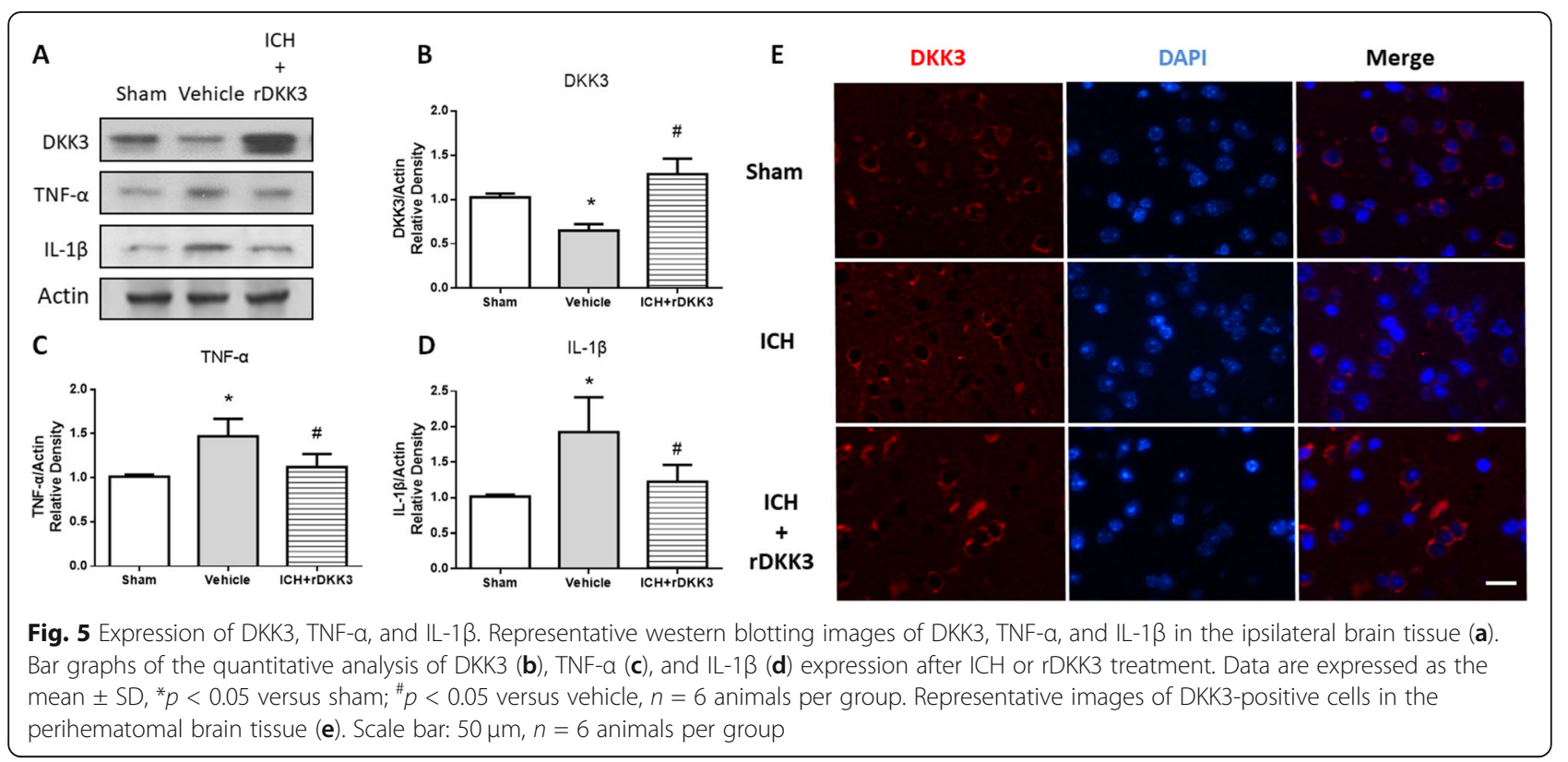

DKK3 and DVL-1 was significantly decreased at $24 \mathrm{~h}$ after ICH (* $p<0.05$ versus sham group; Fig. $7 \mathrm{~b}, \mathrm{~d})$. Additionally, p-JNK, AP-1, cleaved caspase-1, and IL$1 \beta$ were significantly elevated in the vehicle group compared to the sham group $\left({ }^{*} p<0.05\right.$; Fig. 7e-h). rDKK3 administration showed increased DKK3 and DVL-1 expression $\left({ }^{\#} p<0.05\right.$; Fig. $\left.7 \mathrm{~b}, \mathrm{~d}\right)$ and decreased p-JNK, AP-1, cleaved caspase-1, and IL-1 $\beta$ compared to vehicle $\left({ }^{\#} p<0.05\right.$; Fig. $\left.7 \mathrm{e}-\mathrm{h}\right)$. Kremin-1 siRNA and DVL-1 siRNA showed successful knockdown of expression of Kremin-1 and DVL-1 respectively $(" p<0.05$; Fig. 7c, d). Kremin-1 siRNA and DVL-1 siRNA given with rDKK3 showed reversal of expression changes seen from rDKK3 treatments alone. Both Kremin-1 siRNA and DVL-1 siRNA groups showed increasing expression of inflammatory factors p-JNK, AP-1, cleaved caspase-1, and IL-1 $\beta$ compared to sham $\left({ }^{*} p<0.05\right)$ and the scramble siRNA group $\left({ }^{@} p<0.05\right.$; Fig. 7e-h). Additionally, Kremin-1 siRNA showed a significant elevation of AP-1 versus vehicle $\left({ }^{\#} p<0.05\right.$; Fig. $\left.7 \mathrm{f}\right)$, and DVL-1 siRNA showed increase in IL1 $\beta$ compared to vehicle $\left({ }^{\#} p<0.05\right.$; Fig. 7h).

\section{The rDKK3-mediated improvement in neurobehavior functions was reversed with Kremen-1 siRNA or DVL-1 siRNA}

The results showed that the neurobehavior function significantly improved at $24 \mathrm{~h}$ after rDKK3 administration, as evaluated by the modified Garcia test, limb placement test, and corner turn test consistent with our results $\left({ }^{\#} p\right.$ $<0.05$ versus vehicle; Fig. $8 \mathrm{a}-\mathrm{c}$ ). Kremin-1 siRNA and DVL-1 siRNA given with rDKK3 showed reversal of these improvements and showed a significant decrease in neurobehavior scores compared to sham $\left({ }^{*} p<0.05\right.$; Fig. $8 \mathrm{a}-\mathrm{c}$ ).

\section{Discussion}

In this study, we demonstrate that the administration of rDKK3 showed beneficial outcomes following the conditions of $\mathrm{ICH}$. The inflammatory response in $\mathrm{ICH}$ is related to the recruitment of inflammatory cells and to the activation of a series of inflammatory cascades. A reduction in inflammatory infiltrates is associated with an attenuation of brain injury of ICH [36-38]. Previously, DKK3 was observed at high levels in the liver, heart, kidney, and brain [39-42]. DKK3 overexpression substantially alleviated cardiac hypertrophy and fibrosis [10]. We showed that rDKK3 inhibits ICH-induced inflammation, leading to improved neuroprotection after experimental $\mathrm{ICH}$ in mice.

Intranasal administration allows many drugs to avoid $\mathrm{BBB}$ and reach the cerebrospinal fluid via olfactory sensory neurons [43]. Thus, in the present study, rDKK3 was intranasally administered. Three doses of rDKK3 $(0.5 \mu \mathrm{g}, 1.5 \mu \mathrm{g}$, and $5.0 \mu \mathrm{g})$ were evaluated in the $\mathrm{ICH}$ mouse model. Our results showed that treatment with $5.0 \mu \mathrm{g}$ of rDKK3 improved neurological function and reduced cerebral edema at 24 and $72 \mathrm{~h}$ after ICH (Fig. 3). Additionally, we found that long-term neurological deficits were also improved based on the water maze and rotarod experiments (Fig. 4). This suggests that DKK3 may be a neuroprotective therapy in a setting of $\mathrm{ICH}$.

Although it has been shown that DKK3 protects neurons against a variety of toxic insults via mediating vascular endothelial growth factor (VEGF), the complete 


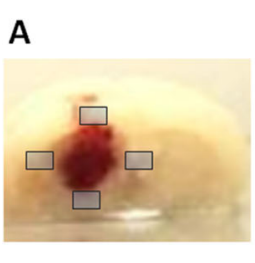

B
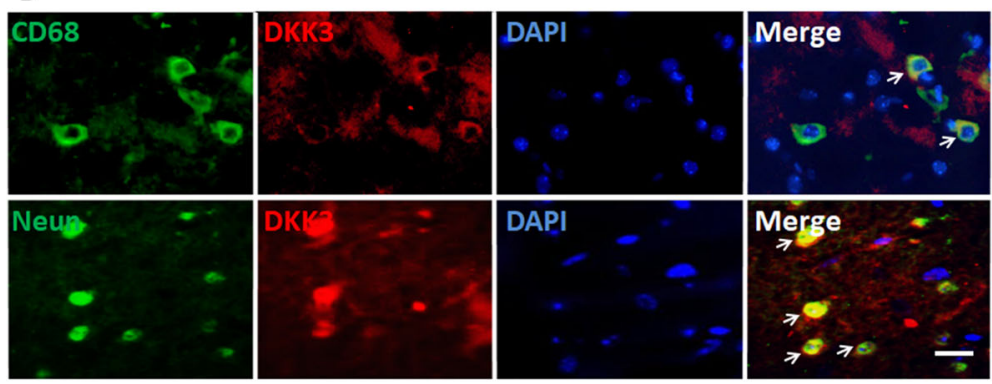

\section{C}
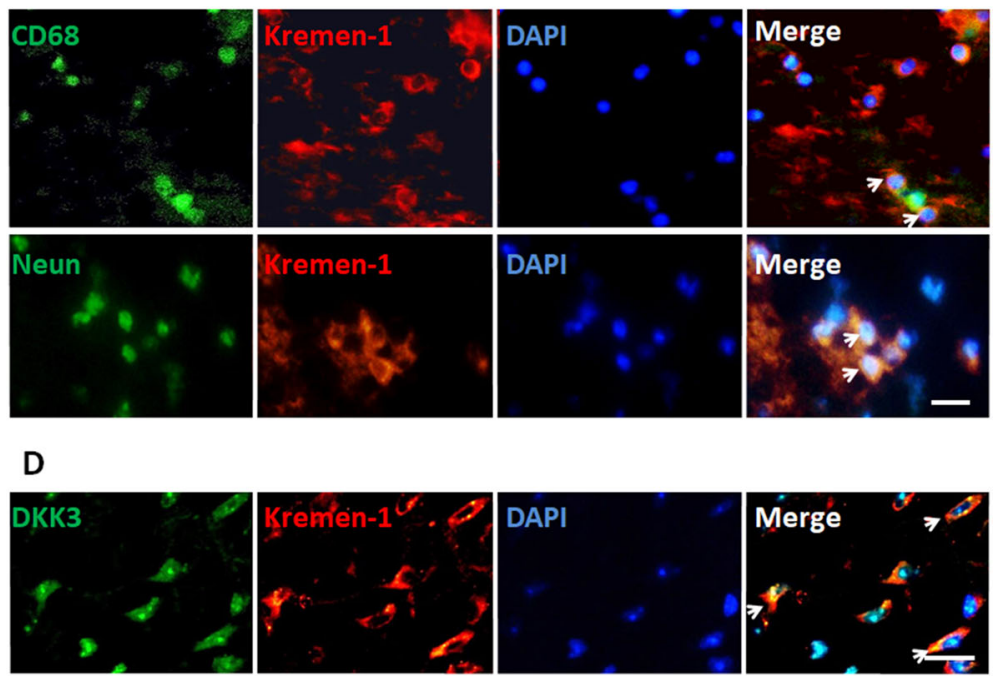

Fig. 6 Endogenous expression of DKK3 and Kremen-1 after ICH in microglia and neurons. Brain samples were obtained from the perihematomal area of the brain tissue (shown with a gray shadow) $24 \mathrm{~h}$ following $\mathrm{ICH}$ (a). Representative images of immunofluorescence staining showing the expression of (b) DKK3 (red) and (c) Kremen-1 (red), colocalizing with the activated microglia marker CD68 (green) and neuronal marker Neun (green). DKK3 (green) colabeled with Kremen-1 (red) (d). Scale bar: $20 \mu m, n=6$ animals per group

biological action of DKK3 is still not fully understood. Previous studies have also shown that DKK3 may reduce activation of inflammatory pathways such as JNK1/2 and p38 pathways as observed in myocardial infarction [9]. In this study, we found that a decreased DKK3 expression was accompanied by an increase of inflammatory factors after ICH. By treating ICH mice with $\mathrm{rDKK} 3$, we observed significant decreases in the release of inflammatory factors such as TNF- $\alpha$, cleaved caspase-1, and IL-1 $\beta$ (Fig. 5). Microglia activation during brain injury and neuroinflammation has previously been linked to the secretion of pro-inflammatory cytokines including IL-1, IL-6, and TNF- $\alpha[44,45]$. In our experiment, we observed that rDKK3 administration decreased the expression of TNF- $\alpha$ and IL-1 $\beta$, suggesting a reduction in microglial activation. These findings suggest that DKK3 may modulate the inflammatory response found after ICH (Figs. 5a, 7a).

The specific receptors and related signaling pathways that DKK3 interacts with are still controversial compared to those of the other DKK family members. It has been proposed that the DKK3-Kremen-1 interaction may affect Wnt signaling [46]. Nicola confirmed that Kremen-1, but not lipoprotein receptor-related protein 6 (LRP6), immunoprecipitated with DKK3 in cancerassociated fibroblasts, and the mRNA levels of Kremen1 were not altered after DKK3 silencing [47]. In the present study, Kremen-1 did not show any change in 


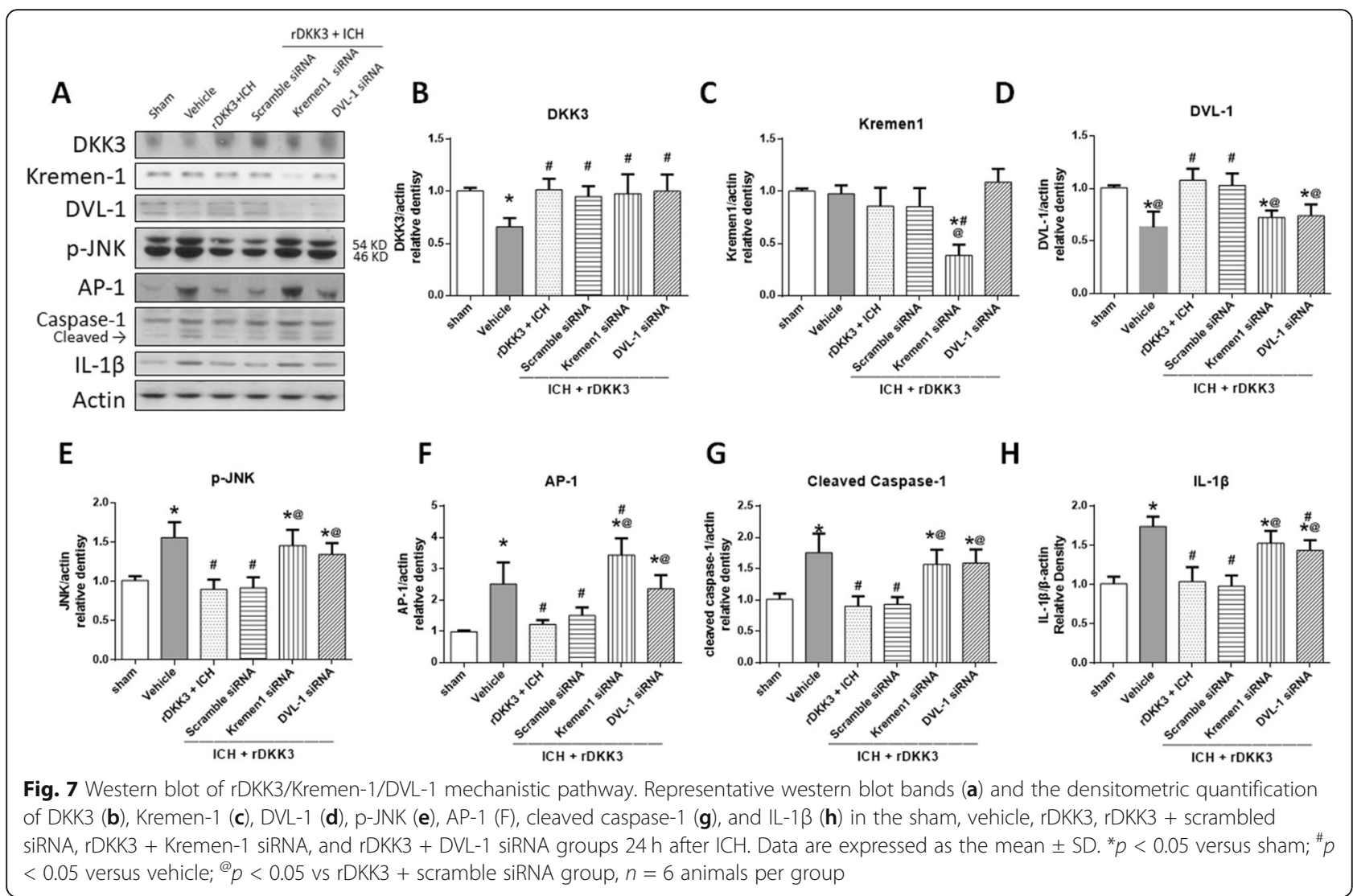

expression during the same timeframe when DKK3 levels were observed to be reduced after ICH. Utilizing Kremin-1 siRNA together with rDKK3 reduced the protective ability shown with rDKK3 alone (Fig. 2). This suggests the connection of DKK3 to the Kremen-1 receptor.

We also found that DKK3 and Kremen-1 were expressed in neurons and microglia after ICH (Fig. 6). Of interest was our observation of the Kremen-1 pattern changes in neurons. Kremen-1 formed a ring at the edge of the cell membrane suggesting it is cell surface membrane bound when there was a reduction in DKK3 as seen during the $\mathrm{ICH}$ setting. This is consistent with other studies such as in a tumor microenvironment where DKK3 and Kremen-1 colocalized to internal structures; however, after DKK3 silencing, Kremen-1 localized to the cell periphery [47]. DKK3 distribution was also found to be disrupted following $\mathrm{ICH}$ injury showing decreased expression (Fig. 5e). These findings suggest that endogenous DKK3 shapes the responsiveness of neurons to inflammatory insults. Previous research has reported endogenous DKK3 decreases ischemic brain damage in mice and acts as a protective molecule in cultured neurons [22]. On human Alzheimer's disease tissue, DKK3 is expressed in neurons and in blood vessel walls in the brain [48]. Consistent with our staining in
Fig. 6b, DKK3 and neurons co-localize. DKK3 was also found which localized to glia in mouse retina [21, 49]. Our immunohistochemical analysis also showed that DKK3 expression was detected in CD68-positive cells. This possibly shows that DKK3 is produced by microglia and stimulates the same microglia to reduce its own activation and acts as a protective molecule. In support of the mechanism, DKK3 overexpression in the liver alleviated chronic inflammation, as evidenced by lower levels of pro-inflammatory cytokines and genes such as IL-1 $\beta$, IL-6, TNF- $\alpha$, MCP-1, and iNOS similar to what we observed in our study [39].

We also found that the ICH injury caused a gradual decline in the endogenous expression of DVL-1 from 12 to $72 \mathrm{~h}$ after ICH. The reduction in DKK3 and DVL-1 after ICH may be a protective mechanism of DKK3. Yu and colleagues also demonstrated that DVL-1 and JNK are potential signaling pathways that relay DKK3 signaling in endothelial cells [50]. However, to our knowledge, we are the first to demonstrate its signaling pathways being potentially associated in microglia. The loss of DKK3 led to the inflammatory cell infiltration accompanied by an increased p-JNK expression in the brain, supporting the deterioration of neurobehavior (Fig. 5).

Based on our results, we suggest that DVL-1 plays a major role in the downstream signaling involved in the 
A

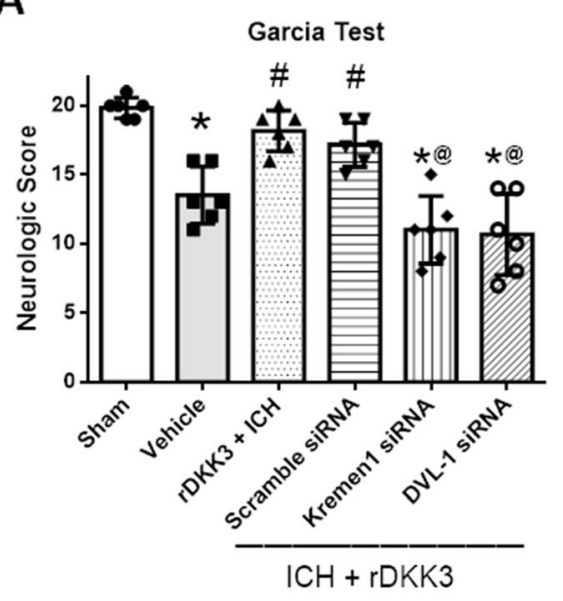

Corner Test

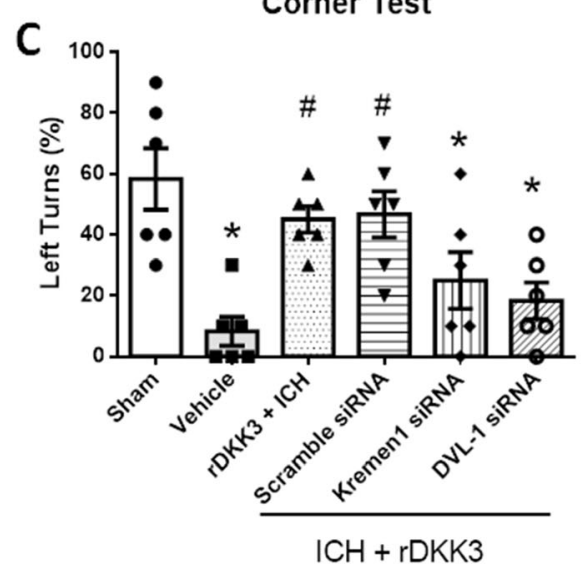

B

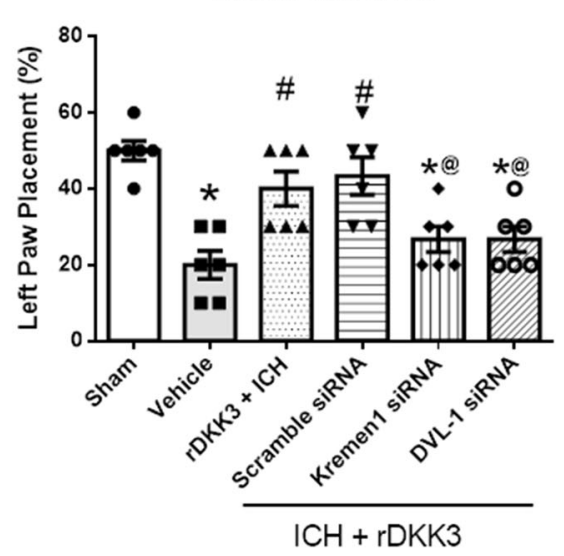

Fig. 8 Neurological function at 24 h showing effects of Kremen-1 and DVL-1 siRNA. Modified Garcia test (a), limb placement test (b), and corner turn test (c) in the sham, vehicle, rDKK3, rDKK3 + Scrambled siRNA, rDKK3 + Kremen-1 siRNA, and rDKK3 + DVL-1 siRNA groups 24 h after ICH. Data are expressed as the mean \pm SD. ${ }^{*} p<0.05$ versus sham; ${ }^{\#} p<0.05$ versus vehicle; ${ }^{@} p<0.05$ vs rDKK3 + scramble siRNA group, $n=6$ animals per group

DKK3 mechanism. These results show that rDKK3 administration increases DVL-1 and decreases JNK, AP-1, cleaved caspase-1, and IL-1 $\beta$ (Fig. 7). DVL-1 is composed of three conserved domains (N-terminal DIX domain, PDZ domain, and a C-terminal DEP domain). Among these, the PDZ domain plays an important role in protein interactions. This domain binds to the membrane-bound receptor and to other signal transduction molecules in the cytoplasm to distinguish between suitable binding partners [51]. Specifically, for the pathways we are exploring, the transmembrane receptor Kremen-1 may compete with the canonical signaling pathway for the interaction with DVL-1 and downstream molecules through its PDZ domain. However, this action of DVL-1 is not dependent on Wnt or its downstream effector $\beta$-catenin. We reduced their expression utilizing Kremen-1 siRNA and DVL-1 siRNA respectively. In the knockdown of either Kremen-1 or DVL-1, the rDKK3- mediated inhibition of inflammation after $\mathrm{ICH}$ is reduced. This suggests that DKK3 forms a ternary complex with Kremen-1 receptors thus allowing fine-tuning of downstream signaling. Furthermore, the neurobehavioral findings indicated that the neuroprotective effect of DKK3 after ICH is mediated by DVL-1 and Kremen-1 (Fig. 8).

Our data strongly suggest that the suppression the downstream protein JNK/AP-1 largely account for the neuroprotective action of DKK3. However, one of the major limitations of this study is that we paid special attention to the involvement of DKK 3 to the Kremen- 1 receptor and that other potential mechanisms have not been investigated. DKK3 has been reported to inhibit inflammation through the noncanonical Wnt signaling pathway in a model of atherosclerosis. This mechanism promoted reendothelialization and induced endothelial cell migration [50]. Furthermore, DKK3 has also been 


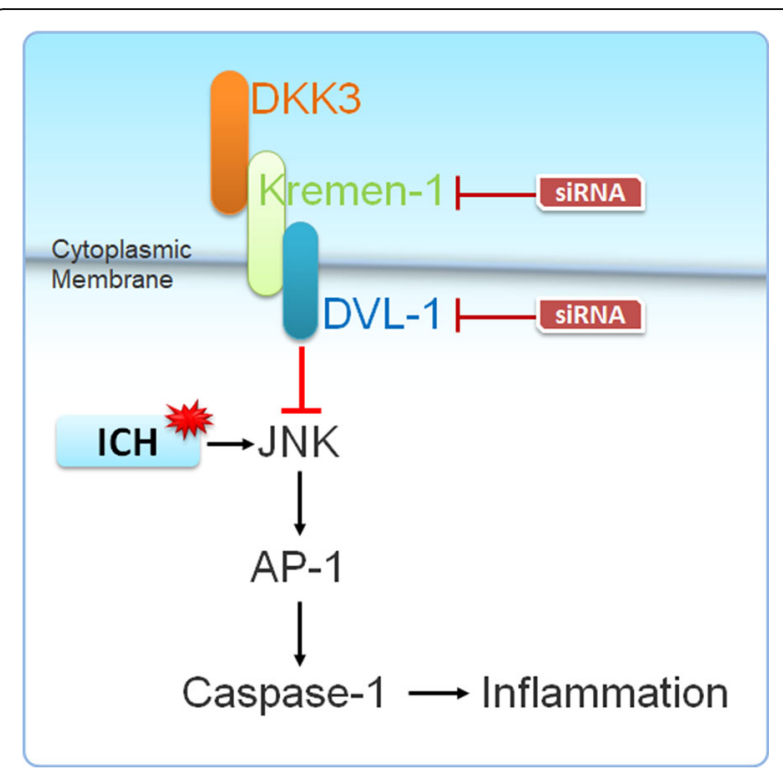

Fig. 9 Mechanism representation in a microglia. ICH induces JNK/ AP-1 activation thus leading to an increase in caspase-1 and producing an inflammatory response. Administration of rDKK3 activates Kremen-1 (phosphorylated) complex with DVL-1, thus reducing JNK/AP-1 signaling and reducing inflammation. Administration of Kremin-1 and DVL-1 siRNA should reduce the effects of DKK3/Kremen-1/DVL-1 thus reducing the beneficial effects of rDKK3 on ICH-induced inflammation

observed in a cardioprotective model to interrupt the ASK1-JNK/p38 signaling cascades [9]. In addition, though we primarily explored the protective effects of DKK3 on the inflammatory process, we also observed that neurons may be affected by other pathways as well potentially contributing to the improved behavioral outcomes we observed. Therefore, DKK3 might represent a promising therapeutic target for $\mathrm{ICH}$ and neuron injury as well.

\section{Conclusion}

This study proposed that DKK3 inhibits the inflammatory reactions induced by $\mathrm{ICH}$. The underlying mechanism of the protective role of DKK3 in $\mathrm{ICH}$ is through Kremen-1 and DVL-1 to inhibit JNK/AP-1 signaling pathway (Fig. 9). The mechanism of DKK3 signaling is complex and is dynamically regulated during brain development through its crosstalk with many signaling pathways. Further research is needed to elucidate the precise mechanism by which DKK3 regulates DVL-1 signaling. Our results indicate a neuroprotective role in reducing inflammation in an experimental model of $\mathrm{ICH}$. Therefore, we propose that DKK3 administration may provide a promising therapy to the pathology of $\mathrm{ICH}$ and brain injury.

\section{Abbreviations}

AP-1: Activator protein-1; Cont-BG: Contralateral basal ganglia; ContCX: Contralateral cortex; CAMKII: Calmodulin-dependent protein kinase II; DKK: Dickkopf; ICH: Intracerebral hemorrhage; IL-1 $\beta$ : Interleukin-1 beta; IpsiBG: Ipsilateral basal ganglia; Ipsi-CX: Ipsilateral cortex; JNK: c-JUN N-terminal kinase; LRP: Lipoprotein receptor-related protein; VEGF: Vascular endothelial growth factor

\section{Acknowledgements}

Not applicable.

\section{Authors' contributions}

$J H Z, Y X$, and JPT conceived and designed the study. YX, HL, LYY, TL, and ZYL performed the experiments and collected the data. DN, TW, and BYL contributed to the analysis of data and drafting of this article. The authors read and approved the final manuscript.

\section{Funding}

This study was supported partially by grants NS091042 and NS082184 from the National Institutes of Health and grants from the National Natural Science Foundation of China (81701161 and 81671143).

\section{Availability of data and materials}

The datasets analyzed during the current study are available from the corresponding author on reasonable request.

\section{Ethics approval and consent to participate}

This study was approved by the Institutional Animal Care and Use Committee at Loma Linda University. All procedures were carried out in compliance with the care and the Use of Laboratory Animals (National Research Council) and complied with the ARRIVE guidelines for reporting in vivo experiments.

\section{Consent for publication}

Not applicable.

\section{Competing interests}

No competing interests.

\section{Author details}

${ }^{1}$ Key Laboratory of Non-coding RNA Transformation Research of Anhui Higher Education Institutes, Wannan Medical College, Wuhu 241000, Anhui, China. ${ }^{2}$ Department of Basic Sciences, Division of Physiology, Loma Linda University School of Medicine, 11041 Campus St, Risley Hall, Room 219, Loma Linda, CA 92350, USA. '3epartment of Neurology, Wannan Medical College First Affiliated Hospital, Wuhu 241000, Anhui, China. ${ }^{4}$ Department of Neurology, The First Affiliated Hospital, School of Medicine, Zhejiang University, Qingchun Road 79, Zhejiang 310003, Hangzhou, China. ${ }^{5}$ Department of Anesthesiology, Loma Linda University School of Medicine, Loma Linda, CA 92350, USA.

Received: 25 November 2019 Accepted: 27 March 2020 Published online: 24 April 2020

\section{References}

1. Joseph MJ, Caliaperumal J, Schlichter LC. After intracerebral hemorrhage, oligodendrocyte precursors proliferate and differentiate inside white-matter tracts in the rat striatum. Translational stroke research. 2016;7(3):192-208.

2. Lu Z, Wang Z, Yu L, Ding Y, Xu Y, Xu N, et al. GCN2 reduces inflammation by $p$-elF2alpha/ATF4 pathway after intracerebral hemorrhage in mice. Exp Neurol. 2019;313:16-25.

3. Lu T, Wang Z, Prativa S, Xu Y, Wang T, Zhang Y, et al. Macrophage stimulating protein preserves blood brain barrier integrity after intracerebral hemorrhage through recepteur d'origine nantais dependent GAB1/Src/betacatenin pathway activation in a mouse model. J Neurochem. 2019;148(1): 114-26.

4. Krafft PR, McBride D, Rolland WB, Lekic T, Flores JJ, Zhang JH. a7 nicotinic acetylcholine receptor stimulation attenuates neuroinflammation through JAK2-STAT3 activation in murine models of intracerebral hemorrhage. BioMed Res Int. 2017;2017:8134653. 
5. Ma L, Manaenko A, Ou YB, Shao AW, Yang SX, Zhang JH. Bosutinib attenuates inflammation via inhibiting salt-inducible kinases in experimenta model of intracerebral hemorrhage on mice. Stroke. 2017:48(11):3108-16.

6. Chen S, Yang $\mathrm{Q}$, Chen $\mathrm{G}$, Zhang JH. An update on inflammation in the acute phase of intracerebral hemorrhage. Translational stroke research. 2015;6(1):4-8

7. Zhang P, Wang T, Zhang D, Zhang Z, Yuan S, Zhang J, et al. Exploration of MST1-mediated secondary brain injury induced by intracerebral hemorrhage in rats via hippo signaling pathway. Transl Stroke Res. 2019; 10(6):729-43.

8. Qui S, Kano J, Noguchi M. Dickkopf 3 attenuates xanthine dehydrogenase expression to prevent oxidative stress-induced apoptosis. Genes to cells : devoted to molecular \& cellular mechanisms. 2017;22(4):406-17.

9. Bao MW, Cai Z, Zhang XJ, Li L, Liu X, Wan N, et al. Dickkopf-3 protects against cardiac dysfunction and ventricular remodelling following myocardial infarction. Basic research in cardiology. 2015;110(3):25.

10. Gu YM, Ma YH, Zhao WG, Chen J. Dickkopf3 overexpression inhibits pancreatic cancer cell growth in vitro. World journal of gastroenterology. 2011;17(33):3810-7.

11. Mizobuchi Y, Matsuzaki K, Kuwayama K, Kitazato K, Mure H, Kageji T, et al. REIC/Dkk-3 induces cell death in human malignant glioma. Neuro-oncology. 2008;10(3):244-53.

12. Than SS, Kataoka K, Sakaguchi M, Murata H, Abarzua F, Taketa C, et al. Intraperitoneal administration of an adenovirus vector carrying REIC/Dkk-3 suppresses peritoneal dissemination of scirrhous gastric carcinoma. Oncology reports. 2011;25(4):989-95.

13. Fujii $Y$, Hoshino $T$, Kumon $H$. Molecular simulation analysis of the structure complex of C2 domains of DKK family members and beta-propeller domains of LRP5/6: explaining why DKK3 does not bind to LRP5/6. Acta Med Okayama. 2014;68(2):63-78.

14. Veeck J, Dahl E. Targeting the Wnt pathway in cancer: the emerging role of Dickkopf-3. Biochimica et biophysica acta. 2012;1825(1):18-28.

15. McEnerney L, Duncan K, Bang BR, Elmasry S, Li M, Miki T, et al. Dual modulation of human hepatic zonation via canonical and non-canonical Wnt pathways. Experimental \& molecular medicine. 2017;49(12):e413.

16. Sumia I, Pierani A, Causeret F. Kremen1-induced cell death is regulated by homo- and heterodimerization. Cell Death Discovery. 2019;5:91.

17. Mulvaney JF, Thompkins C, Noda T, Nishimura K, Sun WW, Lin SY, et al. Kremen1 regulates mechanosensory hair cell development in the mammalian cochlea and the zebrafish lateral line. Sci Rep. 2016;6:31668.

18. Lu D, Bao D, Dong W, Liu N, Zhang X, Gao S, et al. Dkk3 prevents familial dilated cardiomyopathy development through Wnt pathway. Lab Invest. 2016:96(2):239-48

19. Vukic V, Callaghan D, Walker D, Lue LF, Liu QY, Couraud PO, et al. Expression of inflammatory genes induced by beta-amyloid peptides in human brain endothelial cells and in Alzheimer's brain is mediated by the JNK-AP1 signaling pathway. Neurobiology of disease. 2009;34(1):95-106.

20. Al-Dhohorah T, Mashrah M, Yao Z, Huang J. Aberrant DKK3 expression in the oral leukoplakia and oral submucous fibrosis: a comparative immunohistochemical study. Eur J Hist ochem. 2016;60(2):2629.

21. Zhu L, Shen W, Zhang T, Wang Y, Bahrami B, Zhou F, et al. Characterization of canonical Wnt signalling changes after induced disruption of Muller cell in murine retina. Exp Eye Res. 2018;175:173-80.

22. Busceti CL, Di Menna L, Bianchi F, Mastroiacovo F, Di Pietro P, Traficante A, et al. Dickkopf-3 causes neuroprotection by inducing vascular endothelial growth factor. Front Cell Neurosci. 2018;12:292.

23. Karamariti E, Zhai C, Yu B, Qiao L, Wang Z, Potter CMF, et al. DKK3 (Dickkopf 3) alters atherosclerotic plaque phenotype involving vascular progenitor and fibroblast differentiation into smooth muscle cells. Arteriosclerosis Thrombosis Vascular Biol. 2018;38(2):425-37.

24. Zhang Y, Liu Y, Zhu XH, Zhang XD, Jiang DS, Bian ZY, et al. Dickkopf-3 attenuates pressure overload-induced cardiac remodelling. Cardiovascular research. 2014;102(1):35-45.

25. Akazawa H, Komuro I. Dickkopf-3: a stubborn protector of cardiac hypertrophy. Cardiovascular research. 2014;102(1):6-8.

26. Zhai $C G$, Xu YY, Tie $Y Y$, Zhang $Y$, Chen WQ, Ji XP, et al. DKK3 overexpression attenuates cardiac hypertrophy and fibrosis in an angiotensin-perfused animal model by regulating the ADAM17/ACE2 and GSK-3beta/beta-catenin pathways. J Mol Cell Cardiol. 2017;114:243-52.

27. Rolland WB, Lekic T, Krafft PR, Hasegawa Y, Altay O, Hartman R, et al. Fingolimod reduces cerebral lymphocyte infiltration in experimental models of rodent intracerebral hemorrhage. Experimental neurology. 2013;241:45-55.

28. Krafft PR, Altay O, Rolland WB, Duris K, Lekic T, Tang J, et al. alpha7 nicotinic acetylcholine receptor agonism confers neuroprotection through GSK-3beta inhibition in a mouse model of intracerebral hemorrhage. Stroke. 2012;43(3):844-50.

29. Pan C, Liu N, Zhang P, Wu Q, Deng H, Xu F, et al. EGb761 ameliorates neuronal apoptosis and promotes angiogenesis in experimental intracerebral hemorrhage via RSK1/GSK3beta pathway. Mol Neurobiol. 2018; 55(2):1556-67.

30. Tanaka M, Ogaeri T, Samsonov M, Sokabe M. The 5alpha-reductase inhibitor finasteride exerts neuroprotection against ischemic brain injury in aged male rats. Transl Stroke Res. 2019;10(1):67-77.

31. Yang $Y$, Zhang $K$, Yin $X$, Lei $X$, Chen X, Wang J, et al. Quantitative iron neuroimaging can be used to assess the effects of minocycline in an intracerebral hemorrhage minipig model. Transl Stroke Res. 2019. https:// doi.org/10.1007/s12975-019-00739-2.

32. Iniaghe LO, Krafft PR, Klebe DW, Omogbai EKI, Zhang JH, Tang J. Dimethyl fumarate confers neuroprotection by casein kinase 2 phosphorylation of Nrf2 in murine intracerebral hemorrhage. Neurobiology of disease. 2015;82: 349-58.

33. Chen $S$, Zhao L, Sherchan P, Ding Y, Yu J, Nowrangi D, et al. Activation of melanocortin receptor 4 with $\mathrm{RO} 27-3225$ attenuates neuroinflammation through AMPKJNNK/p38 MAPK pathway after intracerebral hemorrhage in mice. J Neuroinflamm. 2018;15(1):106.

34. Chen S, Zuo Y, Huang L, Sherchan P, Zhang J, Yu Z, et al. RO27-3225 attenuates NLRP1-dependent neuronal pyroptosis via MC4R/ASK1/JNK/p38 MAPK pathway in a mouse model of intracerebral hemorrhage. $\mathrm{Br} J$ Pharmacol. 2019;176(9):1341-56.

35. Miao H, Jiang Y, Geng J, Zhang B, Zhu G, Tang J. Edaravone administration confers neuroprotection after experimental intracerebral hemorrhage in rats via NLRP3 suppression. J Stroke Cerebrovasc Dis. 2020;29(1):104468.

36. Wang Z, Zhou F, Dou Y, Tian X, Liu C, Li H, et al. Melatonin alleviates intracerebral hemorrhage-induced secondary brain injury in rats via suppressing apoptosis, inflammation, oxidative stress, DNA damage, and mitochondria injury. Translational stroke research. 2018;9(1):74-91.

37. Wu B, Ma Q, Khatibi N, Chen W, Sozen T, Cheng O, et al. Ac-YVAD-CMK decreases blood-brain barrier degradation by inhibiting caspase-1 activation of interleukin-1beta in intracerebral hemorrhage mouse model. Transl Stroke Res. 2010;1(1):57-64

38. Wang T, Nowrangi D, Yu L, Lu T, Tang J, Han B, et al. Activation of dopamine D1 receptor decreased NLRP3-mediated inflammation in intracerebral hemorrhage mice. J Neuroinflamm. 2018;15(1):2.

39. Xie L, Wang PX, Zhang P, Zhang XJ, Zhao GN, Wang A, et al. DKK3 expression in hepatocytes defines susceptibility to liver steatosis and obesity. Journal of hepatology. 2016;65(1):113-24.

40. Cao Q, Zhang J, Gao L, Zhang Y, Dai M, Bao M. Dickkopf3 upregulation mediates the cardioprotective effects of curcumin on chronic heart failure. Mol Med Rep. 2018;17(5):7249-57.

41. Zhu X, Li W, Li H. miR-214 ameliorates acute kidney injury via targeting DKK3 and activating of Wnt/beta-catenin signaling pathway. Biol Res. 2018;51(1):31.

42. Fukusumi Y, Meier F, Gotz S, Matheus F, Irmler M, Beckervordersandforth R, et al. Dickkopf 3 promotes the differentiation of a rostrolateral midbrain dopaminergic neuronal subset in vivo and from pluripotent stem cells in vitro in the mouse. The Journal of neuroscience : the official journal of the Society for Neuroscience. 2015;35(39):13385-401.

43. Patel GB, Zhou $H$, Ponce $A$, Chen W. Safety evaluation of calcium administered intranasally to mice. International journal of toxicology. 2009; 28(6):510-8.

44. Smith JA, Das A, Ray SK, Banik NL. Role of pro-inflammatory cytokines released from microglia in neurodegenerative diseases. Brain Res Bull. 2012; 87(1):10-20.

45. Paetau S, Rolova T, Ning L, Gahmberg CG. Neuronal ICAM-5 inhibits microglia adhesion and phagocytosis and promotes an anti-inflammatory response in LPS stimulated microglia. Front Mol Neurosci. 2017;10:431.

46. Nakamura RE, Hackam AS. Analysis of Dickkopf3 interactions with Wnt signaling receptors. Growth Factors. 2010;28(4):232-42.

47. Ferrari N, Ranftl R, Chicherova I, Slaven ND, Moeendarbary E, Farrugia AJ, et al. Dickkopf-3 links HSF1 and YAP/TAZ signalling to control aggressive behaviours in cancer-associated fibroblasts. Nature communications. 2019; 10(1):130. 
48. Bruggink KA, Kuiperij HB, Gloerich J, Otte-Holler I, Rozemuller AJ, Claassen $J A$, et al. Dickkopf-related protein 3 is a potential Abeta-associated protein in Alzheimer's Disease. J Neurochem. 2015;134(6):1152-62.

49. Nakamura RE, Hunter DD, Yi H, Brunken WJ, Hackam AS. Identification of two novel activities of the Wnt signaling regulator Dickkopf 3 and characterization of its expression in the mouse retina. BMC Cell Biol. 2007;8:52.

50. Yu B, Kiechl S, Qi D, Wang X, Song Y, Weger S, et al. A cytokine-like protein dickkopf-related protein 3 is atheroprotective. Circulation. 2017;136(11): 1022-36.

51. Lee I, Choi S, Yun JH, Seo SH, Choi S, Choi KY, et al. Crystal structure of the PDZ domain of mouse Dishevelled 1 and its interaction with CXXC5. Biochem Biophys Res Commun. 2017;485(3):584-90.

\section{Publisher's Note}

Springer Nature remains neutral with regard to jurisdictional claims in published maps and institutional affiliations.

Ready to submit your research? Choose BMC and benefit from:

- fast, convenient online submission

- thorough peer review by experienced researchers in your field

- rapid publication on acceptance

- support for research data, including large and complex data types

- gold Open Access which fosters wider collaboration and increased citations

- maximum visibility for your research: over $100 \mathrm{M}$ website views per year

At $\mathrm{BMC}$, research is always in progress.

Learn more biomedcentral.com/submissions 